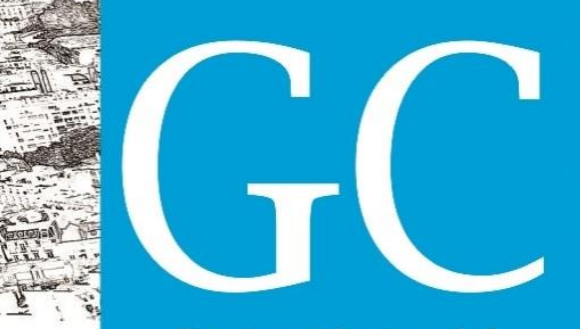

Revista Nacional de

Gerenciamento de Cidades

\title{
EFEITO DA POLUIÇÃO HÍDRICA DEVIDO AO ESCOAMENTO SUPERFICIAL URBANO
}

\author{
José Biscaino Neto ${ }^{1}$ \\ Gabriel Coimbra Rabelo ${ }^{2}$
}

Rosane Freire ${ }^{3}$

\begin{abstract}
RESUMO. Em uma área com influência urbana são através das galerias pluviais que escoam as águas de lavagem atmosférica e da superfície, e estas são encaminhadas para os rios e córregos, juntamente com todos os poluentes presentes nos meios pelos quais passaram. $O$ tipo de poluição descrito é classificado como difusa por ser relacionada aos eventos de chuva e por ser difícil a identificação de um único ponto de origem. Nesse aspecto, esse estudo tem por objetivo investigar a ocorrência de poluição hídrica, de origem difusa, por meio do monitoramento de variáveis físicas, químicas e biológicas das águas superficiais de uma porção urbana da bacia hidrográfica do córrego Limoeiro, em Presidente Prudente - SP, apresentada na forma de carga de poluição hídrica. Para isso, foram amostradas as águas dos cursos d'água de cinco diferentes superfícies urbanas: topo da bacia, residencial, comercial, industrial e zona rural. O monitoramento quantitativo e qualitativo das águas escoadas foi definido nos meses de Novembro de 2014, Janeiro e Março de 2015, todos no período da tarde. A análise dos resultados foi feita por meio da carga de poluição, permitindo assim, concluir que os cursos d'água da bacia hidrográfica em estudo, receberam elevadas cargas poluidoras, pontuais e difusas, considerando as dez variáveis de qualidade monitoradas. Esses valores evidenciaram que a poluição originada pelo lançamento de esgotos industriais, da atividade comercial, entre outras fontes de poluição provenientes das áreas urbanas na bacia, está contribuindo para a degradação e redução da qualidade da água.
\end{abstract}

PALAVRAS-CHAVE: poluição difusa, bacia do Limoeiro, carga poluidora.

\section{EFFECT OF WATER POLLUTION DUE TO SURFACE FLOW URBAN}

\footnotetext{
${ }^{1}$ Graduação em Engenharia Ambiental, UNESP-FCT. E-mail: gabriel.crsp@gmail.com

${ }^{2}$ Graduação em Engenharia Ambiental, UNESP-FCT. E-mail: josebiscainoneto@hotmail.com

${ }^{3}$ Engenheira Ambiental. Professora Assistente Doutora, UNESP-FCT. E-mail: rosane@fct.unesp.br
} 


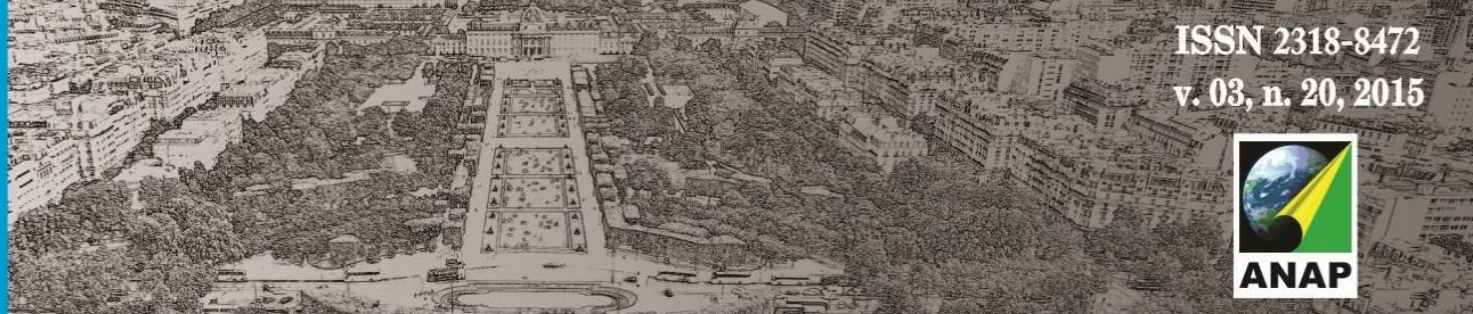

Revista Nacional de

Gerenciamento de Cidades

\begin{abstract}
In an area with urban influence are through the storm sewers that drain the air washing water and the surface, and these are forwarded to the rivers and streams, along with all the pollutants present in the means by which passed. The type of pollution is described by being classified as diffuse related to rain events and be difficult to identify a single point of origin. In this respect, this study aims to investigate the occurrence of water pollution from diffuse sources, by monitoring physical, chemical and biological variables of surface waters of an urban portion of the watershed stream Lemon Tree, in Presidente Prudente - SP, presented in the form of water pollution load. For this, the waters of waterways five different urban surfaces were sampled: the top of the basin, residential, commercial, industrial and rural areas. The quantitative and qualitative monitoring of the disposed water has been set for November 2014, January and March 2015, all in the afternoon. The analysis was done by means of the pollution load, thus, conclude that the waterways of the river basin under study, received high polluting, point and diffuse loads, considering the ten quality variables monitored. These values showed that the pollution caused by the release of industrial waste, commercial activity, among other sources of pollution from urban areas in the basin, is contributing to the degradation and reduced water quality.
\end{abstract}

KEYWORDS: diffuse pollution, basin of Limoeiro, poluidora load.

\title{
EFECTO DE LA CONTAMINACIÓN DEL AGUA POR SUPERFICIE DE FLUJO URBAN
}

\begin{abstract}
RESUMEN. En una zona con influencia urbana son a través de las alcantarillas que drenan el agua de lavado del aire y de la superficie, y estos son enviados a los ríos y arroyos, además de todos los contaminantes presentes en el medio por el que pasaron. El tipo de contaminación se describe por ser clasificado como difuso relacionados a la lluvia eventos y ser difícil identificar un único punto de origen. En este sentido, este estudio tiene como objetivo investigar la ocurrencia de la contaminación del agua de fuentes difusas, mediante el control de las variables biológicas de las aguas superficiales de una parte urbana de la corriente de cuencas Lemon Tree, en Presidente Prudente físicas, químicas y - SP, presentado en forma de carga de contaminación del agua. Para ello, las aguas de los cursos de agua cinco superficies urbanas diferentes fueron muestreados: la parte superior de la cuenca, residencial, comercial, industrial y de las zonas rurales. El seguimiento cuantitativo y cualitativo del agua dispuesta se ha fijado para noviembre de 2014, enero y marzo de 2015, toda la tarde. El análisis se realiza por medio de la carga de contaminación, por lo tanto, la conclusión de que los cursos de agua de la cuenca en estudio, recibieron alta contaminante, punto y cargas difusas, teniendo en cuenta las diez variables de calidad supervisados. Estos valores muestran que la contaminación causada por la liberación de los residuos industriales, la actividad comercial, entre otras fuentes de contaminación de las zonas urbanas de la cuenca, está contribuyendo a la degradación y la reducción de la calidad del agua.
\end{abstract}

PALABRAS CLAVE: contaminación difusa, lavabo Lemon Tree, carga contaminante. 


\section{Revista Nacional de}

Gerenciamento de Cidades

\section{INTRODUÇÃO}

A água é um importante suporte ao desenvolvimento de um dos maiores potenciais de biodiversidade da Terra e de produção da biomassa. Assim, o grande potencial de água deve ser visto como um capital ecológico de inestimável importância e fator competitivo fundamental ao desenvolvimento socioeconômico sustentado (NAIME \& FAGUNDES, 2005).

Entretanto, o homem sempre buscou sua colonização próxima aos recursos hídricos e, segundo Souza (2012), o crescimento acelerado e desordenado da população, geralmente sem infraestrutura adequada em torno de rios, córregos e riachos, gerou uma significativa perda da vegetação marginal, a qual protege o curso d'água, e, consequentemente, uma perda substancial da sua qualidade. Outro fator importante que acarreta perda na qualidade dos cursos d'água é o encaminhamento de materiais e substâncias nocivas ao meio ambiente, a exemplo, de produtos de origem industrial e química (De Souza, 2012).

Em áreas urbanizadas, as redes de drenagem são as principais responsáveis pelo transporte de cargas poluidoras de diversas origens. Essa poluição apresenta-se de forma diversificada e depende de fatores como uso e ocupação do solo, densidade populacional, estações do ano, topografia, geologia e da intensidade e frequência das precipitações (SALGADO, 2013).

Nesse cenário, a finalidade desse estudo foi investigar a ocorrência de poluição hídrica, por meio do monitoramento de variáveis físicas, químicas e biológicas das águas superficiais da porção urbana da bacia hidrográfica do córrego Limoeiro, em Presidente Prudente - SP, apresentada na forma de carga de poluição hídrica.

Com as informações encontradas será possível avaliar o estado de qualidade dos corpos receptores quanto aos fatores que colaboram com a poluição hídrica e assim, contribuir para que outras pesquisas científicas voltadas para o tema sejam desenvolvidas na região do extremo oeste de São Paulo, de modo a 


\section{Revista Nacional de}

Gerenciamento de Cidades

subsidiar tecnicamente as ações adotadas pelos Comitês de Bacias, órgãos ambientais, pelas prefeituras e empresas de saneamento. A finalidade principal é manter a disponibilidade de água, qualitativa e quantitativamente, para todos os usos pretendidos.

\section{OBJETIVOS \\ Objetivo Geral}

O objetivo do estudo foi investigar a ocorrência de poluição hídrica por meio do monitoramento de variáveis físicas, químicas e biológicas das águas superficiais da porção urbana da bacia hidrográfica do córrego Limoeiro, em Presidente Prudente - SP, apresentada na forma de carga de poluição hídrica.

\section{Objetivos Específicos}

Para atingir o objetivo proposto foram necessários os seguintes objetivos específicos:

- alocar os pontos amostrais para o monitoramento das águas superficiais;

- medir a vazão do curso d'água e caracterizar as águas amostradas por meio de variáveis físicas, químicas e biológicas;

- quantificar as cargas poluidoras e construir um banco de informações com os dados qualitativos e quantitativos;

- identificar e definir as causas dos problemas emergentes ou existentes de qualidade de água;

\section{MATERIAIS E MÉTODOS}

A Figura 1 mostra a distribuição espacial dos pontos amostrais alocados na limitação da bacia, sobreposta a uma imagem Landsat 8 de 15/01/2015 (USGS, 2015). 


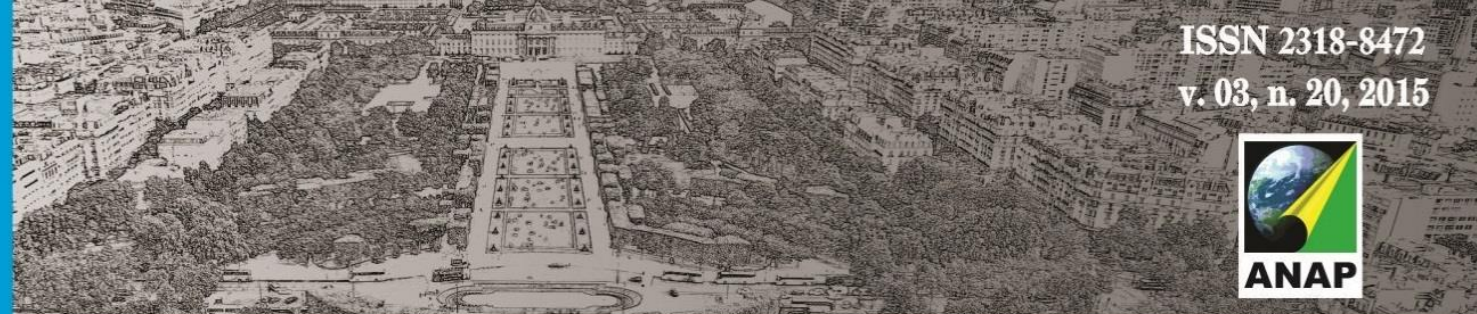

\section{Revista Nacional de \\ Gerenciamento de Cidades}

Figura 1: Pontos amostrais

\section{Legenda}

* Pontos de coleta

Delimitação da bacia

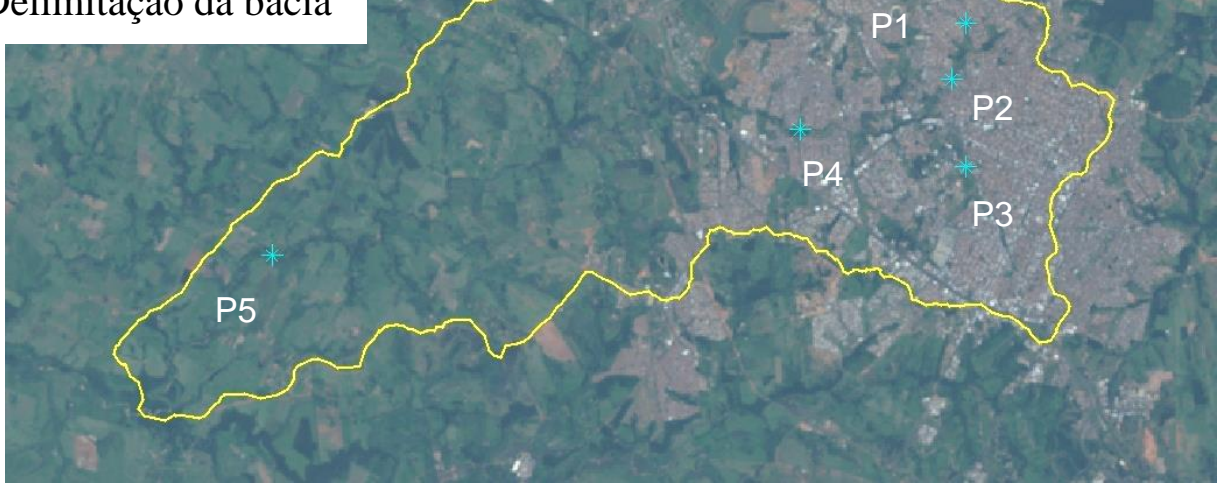

Fonte: SPRING, 2015.

Foram selecionados cinco pontos estrategicamente distintos, sendo os pontos P1 e P2 situados no Córrego Colônia Mineira, respectivamente, no bairro Parque Residencial São Lucas e no bairro Jardim Belo Horizonte. O P1, localizado em uma área de topo da bacia, foi adotado como um ponto de referência devido ao seu possível estado de qualidade e o P2, sobre influência residencial, foi escolhido para verificar a influência da área residencial na alteração da qualidade da água. O córrego se encontra com leito impermeabilizado, como apresentado na Figura 2 e 3.

Figura 2: Ponto de amostragem P1

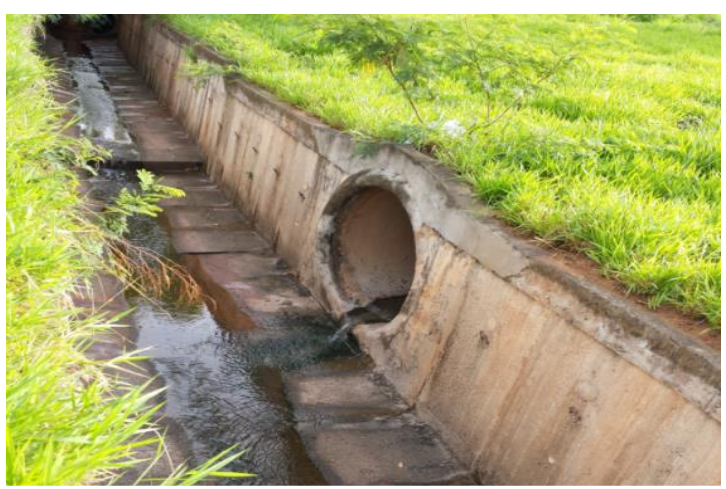

Fonte: AUTOR, 2014.
Figura 3: Ponto de amostragem P2

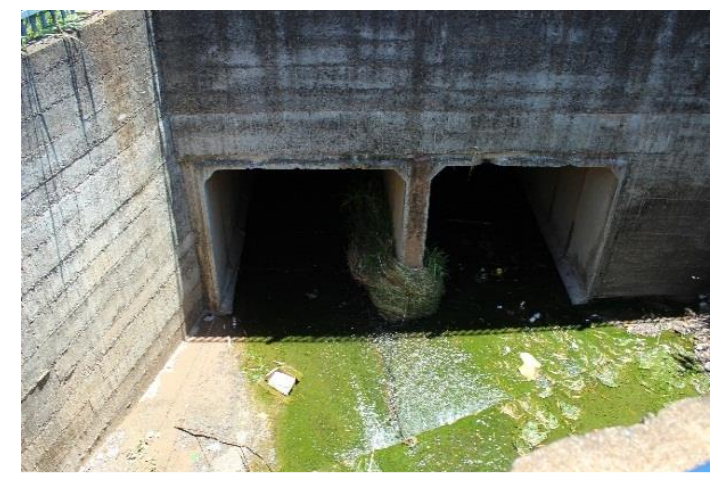

Fonte: AUTOR, 2014.

O ponto P3, situado no Córrego do Veado, no Parque do Povo, encontra-se canalizado e possui influência comercial na área adjacente. O ponto P4 se encontra 


\section{Revista Nacional de}

Gerenciamento de Cidades

coleta de água foi feita utilizando um balde e uma corda. Já nos pontos P1 e P5, devido facilidade de acesso ao corpo d'água, as amostras foram coletadas diretamente no canal, em seu leito vazante, na seção central do curso d'água.

As amostras coletadas foram armazenadas em garrafas de Politereftalato de etileno (PET), com capacidade de $2 \mathrm{~L}$, e em recipiente de vidro âmbar, de $250 \mathrm{~mL}$. Ambos foram limpos previamente, conforme recomendação descrita em APHA (1998), e acondicionados em uma caixa de isopor com gelo para transporte.

In loco foram realizadas a medição da temperatura $\left(\mathrm{T}-{ }^{\circ} \mathrm{C}\right)$ e a do Oxigênio Dissolvido (OD - mg/L), utilizando termômetro de mercúrio e oxímetro HANNA (HI 9146), respectivamente.

As outras análises de caracterização das amostras de água foram realizadas na Central de Laboratórios de Química da Faculdade de Ciências e Tecnologia da UNESP. A caracterização das águas urbanas foi estabelecida por meio da medida de sólidos totais (ST - mg/L), sólidos dissolvidos (SDT - $\mathrm{mg} / \mathrm{L}$ ), sólidos suspensos (SST - mg/L), demanda bioquímica de oxigênio (DBO - mg/L), demanda química de oxigênio (DQO - $\mathrm{mg} / \mathrm{L})$, nitrogênio total Kjeldahal (NTK $\mathrm{mg} / \mathrm{L})$, fósforo total ( $\mathrm{mg} / \mathrm{L}$ ), coliformes totais (CT - NMP/100mL) e coliformes termotolerantes (CTermo $\mathrm{NMP} / 100 \mathrm{~mL}$ ) seguindo os procedimentos analíticos de amostragem, preservação e execução descritos em APHA (1998).

As medidas de vazão das águas superficiais foram determinadas pelo método indireto, empregando flutuadores para estimativa da velocidade das águas, seguindo as recomendações de Palhares et al. (2007). No meio natural, a seção transversal de referência pode ser determinada pela composição de verticais. Inicialmente, se obtém largura da seção do rio, com auxílio de uma trena. Em seguida, a seção é dividida em uma série de verticais igualmente separadas, onde serão medidas suas respectivas profundidades. O cálculo da área da seção transversal foi dado pela soma das áreas de influência formadas em cada vertical, como apresentado na Equação 1. A área de influência para cada vertical pode ser 


\section{Revista Nacional de}

Gerenciamento de Cidades

dada pelo produto entre distância média entre cada vertical e a profundidade. Nas margens considera-se a área como sendo a aproximação da área de um triângulo.

$$
A_{T}=\sum_{i=1}^{n} A i
$$

em que:

$\mathrm{A}_{\mathrm{T}}=$ Área da seção transversal $\left(\mathrm{m}^{2}\right)$;

$\mathrm{n}=$ número de verticais;

$A i=$ Área transversal na seção $i\left(m^{2}\right)$.

Com o intuito de facilitar o entendimento na análise dos resultados das amostras coletadas, a quantificação da carga de poluentes foi determinada por meio do método descrito em Von Sperling (2007), que consiste no produto dos valores de concentração de poluentes, determinados para cada ponto monitorado, pela vazão do rio, visto na Equação 2, A carga poluente foi determinada para todos os parâmetros de qualidade supracitados.

$$
\text { Carga }=C x Q[\mathrm{~kg} / \mathrm{dia}]
$$

Sendo que:

C: Concentração dos Poluentes [kg/L];

Q: Vazão dos pontos de coleta [L/dia].

Finalizou-se o trabalho experimental, diagnosticando as possíveis origens das cargas de poluição das águas urbanas da bacia em estudo. O mesmo foi composto pela análise final dos resultados encontrados de modo a divulgar os problemas emergentes ou existentes de qualidade da água e antever quais as ações de controle estruturais e não estruturais que devem ser realizadas. 


\section{RESULTADOS E DISCUSSÃO}

A partir dos resultados apresentados na Figura 1 foi possível observar os padrões de precipitação nos meses estudados.

Figura 7: Precipitação mensal ocorrida no ano de 2014/15.

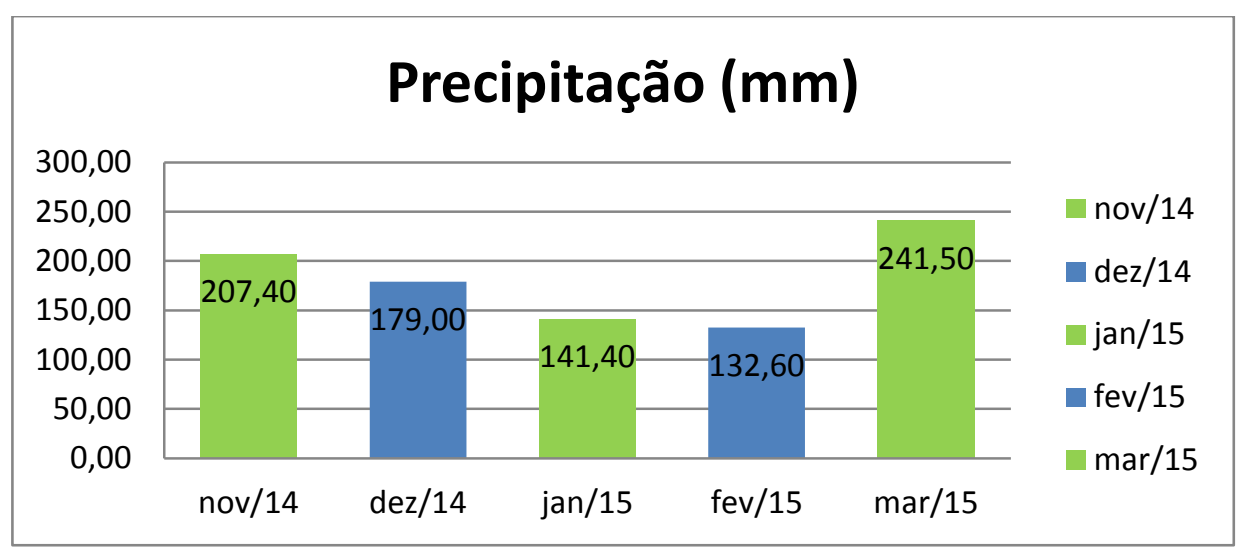

Fonte: INMET (Instituto Nacional de Meteorologia)

Observando a Figura 7, destacaram-se em verde os meses que ocorreram as coletas, sendo eles, Novembro de 2014, Janeiro e Março de 2015, com precipitações de, aproximadamente, 207, 141 e $241 \mathrm{~mm}$, respectivamente. Notou-se que as maiores incidências de precipitação ocorreram justamente nos meses de novembro de 2014 e março de 2015.

Para o presente estudo, foi relevante quantificar a precipitação diária para os meses de novembro/2014, janeiro e março de 2015, quando foram realizadas as coletas amostrais para posterior análise. A Figura 8 ilustra de forma gráfica os volumes precipitados, com sinalização do volume precipitado nos dias de coleta amostral (seta vermelha). 
Figura 8: Precipitação diária ocorrida nos meses de novembro/2014, janeiro e março de 2015.

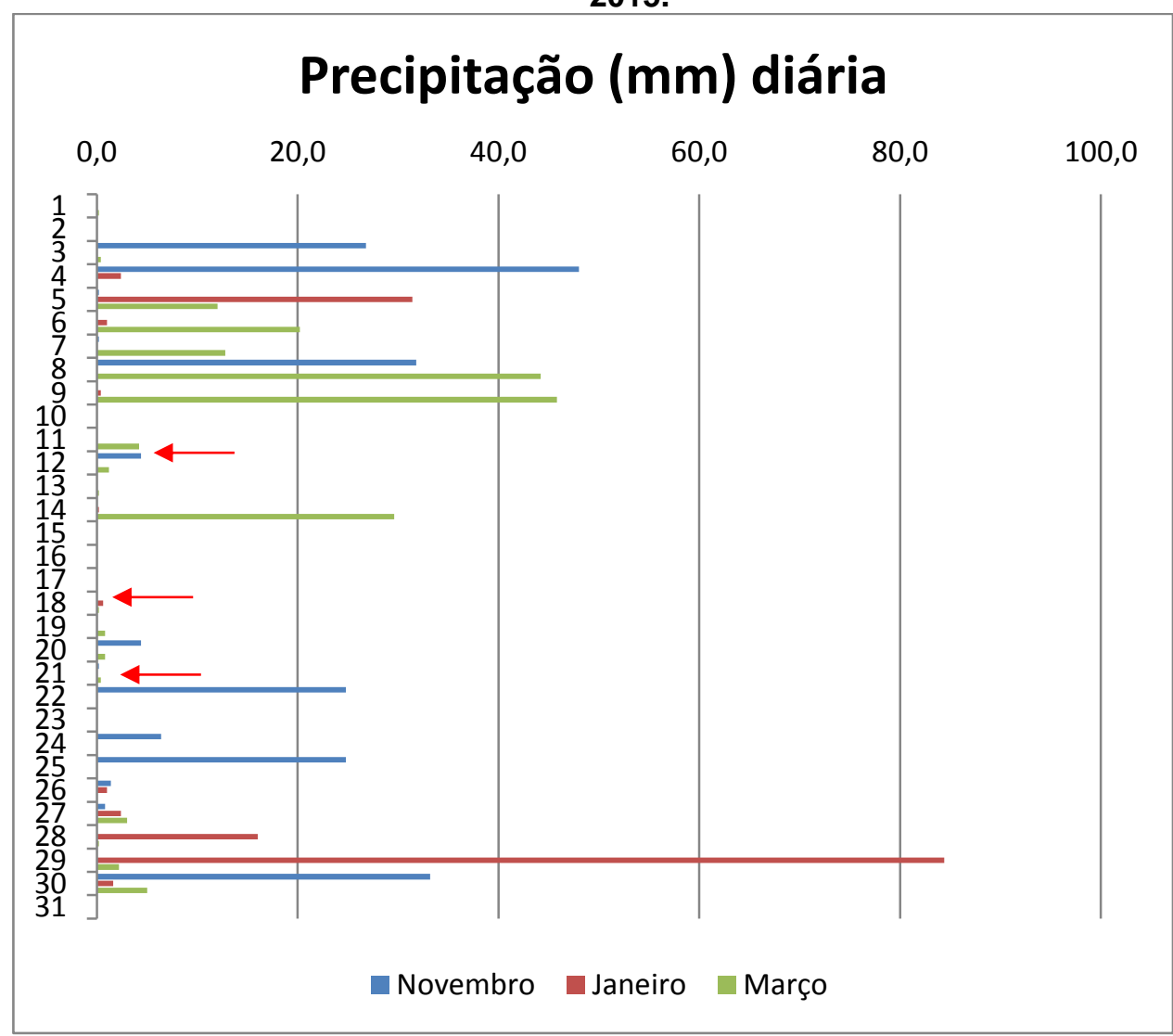

Fonte: INMET (Instituto Nacional de Meteorologia). Adaptado.

Por meio da Figura 8, pode-se perceber que foram três meses relativamente chuvosos e nas coletas de novembro e março houveram a ocorrência de chuva, mas não durante a coleta. Porém, não se pode descartar o fato que as precipitações ocorridas dias antes das coletas tenham interferido ou alterado os valores de concentrações das variáveis estudadas. Com a presença de chuvas, há um incremento de vazão do curso d'água, podendo proporcionar um aumento da carga poluidora pelas fontes de poluição de origem difusa.

As Tabelas 1, 2 e 3 apresentam os valores das concentrações das variáveis monitoradas e a vazão $(Q)$, para os cinco pontos de monitoramento, nos meses de novembro, janeiro e março, respectivamente. 
Revista Nacional de

Gerenciamento de Cidades

Tabela 1: Valores de concentrações dos Parâmetros de Qualidade e Vazão de cada ponto de coleta do mês de Novembro/2014.

\begin{tabular}{c|r|r|r|r|r}
\hline \multirow{2}{*}{ Variáveis } & \multicolumn{5}{|c}{ Pontos Monitorados } \\
\cline { 2 - 6 } & Ponto 1 & Ponto 2 & Ponto 3 & Ponto 4 & \multicolumn{1}{c}{ Ponto 5 } \\
\hline OD (mg /L) & 6,17 & 8,40 & 4,02 & 5,54 & 5,53 \\
\hline DQO (mg /L) & 20,34 & 8,67 & 117,00 & $1.732,00$ & 20,34 \\
\hline DBO (mg /L) & 4,76 & 2,47 & 24,65 & 44,80 & 4,36 \\
\hline ST (mg/L) & 200,00 & 150,00 & 350,00 & $7.950,00$ & 250,00 \\
\hline SS (mg/L) & 4,00 & 30,00 & 135,50 & $2.262,50$ & 41,50 \\
\hline SD (mg/L) & 196,00 & 120,00 & 214,50 & $5.687,50$ & 208,50 \\
\hline FT (mg/L) & 2,58 & 7,95 & 10,03 & 106,31 & 6,24 \\
\hline NTK (mg/L) & 200,00 & 25,00 & $2.500,00$ & $15.650,00$ & 500,00 \\
\hline CT (NMP/L) & $429.000,00$ & $418.000,00$ & $14.000,00$ & $165.000,00$ & $209.000,00$ \\
\hline CTermo & $1.000,00$ & $72.000,00$ & 0,00 & $87.000,00$ & $46.000,00$ \\
\hline (NMP/L) & $5,06.10^{5}$ & $37,48.10^{5}$ & $119,02.10^{5}$ & $539,75.10^{5}$ & $3444,89.10^{5}$ \\
\hline Q (L/dia) &
\end{tabular}

Fonte: AUTOR, 2015

Tabela 2: Valores de concentrações dos Parâmetros de Qualidade e Vazão de cada ponto de coleta do mês de Janeiro/2015.

\begin{tabular}{c|r|r|r|r|r}
\hline \multirow{2}{*}{ Variáveis } & \multicolumn{6}{|c}{ Pontos Monitorados } \\
\cline { 2 - 6 } & Ponto 1 & Ponto 2 & Ponto 3 & \multicolumn{1}{c}{ Ponto 4 } & \multicolumn{1}{c}{ Ponto 5 } \\
\hline OD (mg /L) & 5,70 & 9,81 & 5,56 & 7,35 & 11,40 \\
\hline DQO (mg /L) & 0,00 & 130,30 & 308,67 & 910,33 & 413,67 \\
\hline DBO (mg /L) & 2,83 & 2,19 & 39,75 & 158,00 & 22,00 \\
\hline ST (mg/L) & 60,13 & 93,07 & 98,27 & 183,07 & 135,20 \\
\hline SS (mg/L) & 0,00 & 0,93 & 7,47 & 50,13 & 1,87 \\
\hline SD (mg/L) & 60,13 & 92,13 & 90,80 & 132,93 & 133,33 \\
\hline FT (mg/L) & 0,66 & 1,61 & 2,06 & 15,55 & 11,04 \\
\hline NTK (mg/L) & 0,00 & 0,00 & 1,40 & 9,24 & 0,56 \\
\hline CT (NMP/L) & $11.050,00$ & $8.200,00$ & $8.500,00$ & $41.250,00$ & $3.850,00$ \\
\hline CTermo & $6.650,00$ & 700,00 & $43.750,0$ & \multirow{2}{*}{$48.750,00$} & $1.800,00$ \\
\hline (NMP/L) & $3,32.10^{5}$ & $73,36.10^{5}$ & $46,74.10^{5}$ & $378,53.10^{5}$ & $2.540,5.10^{5}$ \\
\hline Q (L/dia) & & & &
\end{tabular}

Fonte: AUTOR, 2015 
Revista Nacional de

Gerenciamento de Cidades

Tabela 3: Valores de concentrações dos Parâmetros de Qualidade e Vazão de cada ponto de coleta do mês de Março/2015.

\begin{tabular}{c|r|r|r|r|r}
\hline \multirow{2}{*}{ Variáveis } & \multicolumn{6}{|c}{ Pontos Monitorados } \\
\cline { 2 - 6 } & Ponto 1 & Ponto 2 & Ponto 3 & Ponto 4 & Ponto 5 \\
\hline OD (mg /L) & 7,40 & 6,92 & 5,50 & 6,42 & 5,72 \\
\hline DQO (mg /L) & 40,00 & 52,50 & 48,75 & 111,25 & 77,50 \\
\hline DBO (mg /L) & 0,58 & 0,00 & 0,99 & 0,00 & 0,00 \\
\hline ST (mg/L) & 86,53 & 105,20 & 106,13 & 145,60 & 102,00 \\
\hline SS (mg/L) & 3,80 & 5,33 & 4,40 & 11,60 & 6,00 \\
\hline SD (mg/L) & 82,73 & 99,87 & 101,73 & 134,00 & 96,00 \\
\hline FT (mg/L) & 0,52 & 0,12 & 12,72 & 5,46 & 6,08 \\
\hline NTK (mg/L) & 0,00 & 0,00 & 0,84 & 2,52 & 1,12 \\
\hline CT (NMP/L) & $25.000,0$ & $13.500,00$ & $8.750,00$ & $35.000,00$ & $20.000,00$ \\
\hline CTermo & 7.500 & 1.500 & 10.000 & 6.250 & 5.000 \\
(NMP/L) & & & & & 2.000 \\
\hline Q(L/dia) & $1,73.10^{5}$ & $245,34.10^{5}$ & $35,89.10^{5}$ & $483,13.10^{5}$ & $2.511,0.10^{5}$ \\
\hline
\end{tabular}

Fonte: AUTOR, 2015

As Tabelas 4, 5 e 6 apresentam os valores de carga das variáveis monitoradas e que foram transportadas ao longo da bacia hidrográfica durante 0 período de monitoramento: novembro/14, janeiro e março de 2015, respectivamente.

Tabela 4: Valores de cargas dos Parâmetros de Qualidade de cada ponto de coleta para o mês de Novembro/2014.

\begin{tabular}{c|r|r|r|r|r}
\hline \multirow{2}{*}{ Variáveis } & \multicolumn{6}{|c}{ Pontos Monitorados } \\
\cline { 2 - 6 } & Ponto 1 & Ponto 2 & Ponto 3 & \multicolumn{1}{c}{ Ponto 4 } & \multicolumn{1}{c}{ Ponto 5 } \\
\hline OD (kg/dia) & 3,12 & 31,49 & 47,85 & 299,02 & $1.905,02$ \\
\hline DQO (kg/dia) & 10,29 & 32,50 & $1.392,57$ & $93.483,99$ & $7.006,90$ \\
\hline DBO (kg/dia) & 2,41 & 9,26 & 293,39 & $2.418,06$ & $1.501,97$ \\
\hline ST (kg/dia) & 101,23 & 562,25 & $4.165,80$ & $429.097,98$ & $86.122,19$ \\
\hline SS (kg/dia) & 2,02 & 112,45 & $1.612,76$ & $122.117,51$ & $14.296,28$ \\
\hline SD (kg/dia) & 99,20 & 449,80 & $2.553,04$ & $306.980,47$ & $71.825,90$ \\
\hline FT (kg/dia) & 1,31 & 29,80 & 119,38 & $5.738,04$ & $2.149,61$ \\
\hline NTK (kg/dia) & 101,23 & 93,71 & $29.755,71$ & $844.702,31$ & $172.244,37$ \\
\hline CT (NMP/dia) & 217.130 & 1.566 .797 & 166.631 & 8.905 .807 & 71.998 .147 \\
\hline $\begin{array}{c}\text { CTermo } \\
\text { (NMP/dia) }\end{array}$ & 506 & 269.879 & 0,00 & 4.695 .789 & 15.846 .482 \\
\hline
\end{tabular}

Fonte: AUTOR, 2015. 
Revista Nacional de

Gerenciamento de Cidades

Tabela 5: Valores de cargas dos Parâmetros de Qualidade de cada ponto de coleta no mês de Janeiro/2015.

\begin{tabular}{c|r|r|r|r|r}
\hline \multirow{2}{*}{ Variáveis } & \multicolumn{6}{|c}{ Pontos Monitorados } \\
\cline { 2 - 6 } & Ponto 1 & Ponto 2 & Ponto 3 & Ponto 4 & \multicolumn{1}{c}{ Ponto 5 } \\
\hline OD (kg/dia) & 1,89 & 71,97 & 25,99 & 278,22 & $2.896,19$ \\
\hline DQO (kg/dia) & 0,00 & 955,88 & $1.442,72$ & $34.458,72$ & $105.093,69$ \\
\hline DBO (kg/dia) & 0,94 & 16,07 & 185,79 & $5.980,77$ & $5.589,14$ \\
\hline ST (kg/dia) & 19,96 & 682,76 & 459,31 & $6.929,75$ & $34.347,83$ \\
\hline SS (kg/dia) & 0,00 & 6,82 & 34,91 & $1.897,57$ & 475,08 \\
\hline SD (kg/dia) & 19,96 & 675,87 & 424,40 & $5.031,80$ & $33.872,75$ \\
\hline FT (kg/dia) & 0,22 & 11,81 & 9,63 & 588,61 & $2.804,73$ \\
\hline NTK (kg/dia) & 0,00 & 0,00 & 6,54 & 349,76 & 142,27 \\
\hline CT (NMP/dia) & 3.669 & 60.155 & 39.729 & 1.561 .436 & 9.78100 \\
\hline CTermo (NMP/dia) & 2.208 & 5.135 & 204.487 & 1.845 .334 & 457.294 \\
\hline Fon AUTOR, 2015 & & & & &
\end{tabular}

Fonte: AUTOR, 2015.

Tabela 6: Valores de cargas dos Parâmetros de Qualidade de cada ponto de coleta no mês de Março/2015.

\begin{tabular}{c|r|r|r|r|r}
\hline \multirow{2}{*}{ Variáveis } & \multicolumn{6}{|c}{ Pontos Monitorados } \\
\cline { 2 - 6 } & Ponto 1 & Ponto 2 & Ponto 3 & Ponto 4 & \multicolumn{1}{c}{ Ponto 5 } \\
\hline OD (kg/dia) & 1,28 & 169,78 & 19,74 & 310,17 & $1.436,29$ \\
\hline DQO (kg/dia) & 6,91 & $1.288,06$ & 174,96 & $5.374,86$ & $19.460,25$ \\
\hline DBO (kg/dia) & 0,10 & 0,00 & 3,55 & 0,00 & 0,00 \\
\hline ST (kg/dia) & 14,95 & $2.581,03$ & 380,89 & $7.034,43$ & $25.612,20$ \\
\hline SS (kg/dia) & 0,66 & 130,77 & 15,79 & 560,44 & $1.506,60$ \\
\hline SD (kg/dia) & 14,30 & $2.450,26$ & 365,10 & $6.473,99$ & $24.105,60$ \\
\hline FT (kg/dia) & 0,09 & 2,94 & 45,65 & 263,79 & $1.526,69$ \\
\hline NTK (kg/dia) & 0,00 & 0,00 & 3,01 & 121,75 & 281,23 \\
\hline CT (NMP/dia) & 4.320 & 331.215 & 31.403 & 1.690 .967 & 5.022 .000 \\
\hline CTermo (NMP/dia) & 1.296 & 36.802 & 35.889 & 301.958 & 1.255 .500 \\
\hline
\end{tabular}

Fonte: AUTOR, 2015.

Por meio dos resultados apresentados na Tabela 4, foi possível observar uma alta carga de sólidos presentes nas águas da bacia do córrego do Limoeiro. Tal fato, pode ser devido a ocorrência de precipitação no dia da coleta, em que água do escoamento superficial urbano teria uma grande quantidade desse resíduo, aumentando assim, as cargas de sólidos totais, dissolvidos e suspensos. O ponto 4 apresentou a maior carga de sólidos totais, porém, além de sofrer a influência do 
Revista Nacional de

Gerenciamento de Cidades

escoamento superficial, o valor obtido também pode ser justificado pela proximidade das indústrias.

Já nas Tabelas 5 e 6, observaram-se uma alta carga de sólidos no ponto 5 , o qual sofre influência de todos os outros pontos estudados e também da ETE. Em condições naturais, devido a distância do ponto 5 , em relação aos demais, os sólidos presentes deveriam se diluir ao logo curso d'água, porém, não foi o que ocorreu. Outro motivo determinante para o alto valor encontrado, pode ser explicado pelo fato do ponto 5 possuir a maior vazão e, consequente, contribuindo para que a carga transportada seja maior.

Em relação à carga de DBO presente nos pontos estudados, pode-se observar que, os pontos 4 e 5 , tanto nos meses de novembro/14 e janeiro de 2015, apresentaram cargas muito superiores aos demais. $O$ resultado pode ser explicado pelo fato que as principais fontes de matéria orgânica para os referidos pontos são possíveis despejos industriais, principalmente considerando que próximo ao ponto 4 localizam-se empresas de frigorífico e um curtume. Outro fator importante a ser ressaltado é que nos meses de novembro/14 e janeiro de 2015 foram identificadas as maiores vazões, ou seja, a vazão se comporta como um fator limitante para o valor quantificado da carga de DBO. Um resultado semelhante foi obtido em um estudo realizado no rio Ribeirão Maringá (PR), em que também se determinou as cargas poluidoras transportadas devido a presença de industrias e uma ETE (FREIRE et al., 2013).

Com excesso de matéria orgânica, e consequentemente, um elevado teor de DQO, foi observado uma diminuição da concentração de OD. Nos três meses de coleta, isso ficou evidente nos pontos 3 e 4 , em que os valores de concentração da DQO estavam muito superiores aos outros pontos e O OD dos mesmos estavam baixos. Esses efluentes comerciais e industriais contêm uma elevada carga poluente orgânica e inorgânica. Ainda, essas cargas orgânicas podem conter grandes quantidades de agentes microbiológicos, como observado nas Tabelas 4, 5 e 6 . Ao serem descarregados como águas residuárias nos cursos d'água receptores, esses 


\section{Revista Nacional de}

Gerenciamento de Cidades

microrganismos, em excesso, consomem $O$ OD da água para suas atividades biológicas. Além disso, esses agentes microbiológicos constituem uma ameaça significante para a saúde da população que, por algum motivo, faz uso desse corpo hídrico.

Em relação à presença de coliformes totais e termotolerantes, as Tabelas 4, 5 e 6 indicaram que todos os pontos de coleta apresentaram uma grande quantidade de microrganismos, com exceção da amostra de número 3 , do mês de novembro, a qual não registrou nenhum tipo de CTermo. Ficou evidente que os despejos domésticos, comerciais e industriais colaboram para um agravamento da qualidade do curso d'água, podendo causar danos mais severos para a vida aquática do mesmo.

Vale ressaltar que a carga de coliformes totais obteve-se um valor muito alto no ponto 1, para os meses estudados, e isso torna-se um grande desafio na investigação, pois esse ponto foi escolhido como referência para os demais por localizar-se na região de nascente do córrego. Como a área, onde se localiza o ponto amostral, encontra-se inserida em uma praça, uma justificativa a isso pode ser vinculada ao manejo de animais de grande porte em áreas urbanas, ou seja, havendo a ocorrência de defecação de algum animal nas vias publicas, e posteriormente, as águas de escoamento pode ter transportado os microrganismos presentes na superfície do solo para o córrego.

Em relação às cargas de fósforos totais, os pontos 4 e 5 dos três meses de coleta, foram aqueles com valores mais elevados. Os valores do quarto ponto de monitoramento podem ser justificados pelo fato de se localizar após um conjunto industrial de frigoríficos e curtume, onde pode ter ocorrido um despejo significativo contento fósforos e derivados. Já no ponto 5 , é possível estabelecer uma relação de efeito, pelo fato de se localizar após o ponto 4 , ou seja, mesmo distante, a concentração elevada do ponto anterior não foi diluída naturalmente, apresentando assim, uma quantidade significativa de fósforo total. 


\section{Revista Nacional de}

Gerenciamento de Cidades

Em relação à presença de nitrogênio indicados nas Tabelas 4, 5 e 6, ficou evidente, para o mês de novembro, que há fontes de poluição por toda a bacia, sendo que os menores valores de carga foram identificados nos pontos 1 e 2 , o primeiro localizado no topo de bacia e o segundo, próximo a um conjunto de residências. Já no mês de janeiro e março, a poluição por nitrogênio ainda existe, porém com menor intensidade nos pontos 3,4 e 5 , e inexistente nos pontos 1 e 2 . Logo, é possível associar que as áreas com influências comerciais e industriais são as que mais prejudicaram as condições de qualidade das águas dos corpos hídricos da bacia.

Por meio dos valores de cargas poluidoras obtidos pode-se observar que a bacia do Limoeiro vem recebendo um considerável aporte diário, tanto de sólidos quanto de matéria orgânica e nutrientes, provenientes de diversas fontes (pontuais e difusas), as quais podem ser atribuídas principalmente aos despejos domésticos, industriais e a ação do escoamento superficial urbano após eventos pluviométricos.

\section{CONCLUSÃO}

Diante do exposto, conclui-se que os cursos d'água da bacia do Córrego do Limoeiro inseridos na área urbana do município de Presidente Prudente, receberam elevadas cargas poluidoras, considerando as dez variáveis monitoradas. Esses valores evidenciaram que a poluição originada pelo lançamento de esgotos industriais, da atividade comercial, entre outras fontes de poluição provenientes das áreas urbanas na bacia estão contribuindo para a degradação e redução da qualidade da água.

Portanto, pode-se concluir que o ecossistema aquático da bacia do córrego Limoeiro está comprometido. Para evitar maiores e futuros prejuízos ao corpo hídrico é de extrema importância intensificar a fiscalização e o monitoramento da bacia hidrográfica, assim como conscientizar donos de indústrias, comércios e toda a população do município de Presidente Prudente de que suas ações, podem alterar todo um ecossistema aquático, desencadeando sérios problemas ambientais. 
